\title{
The severe thunderstorm of 4 October 2007 in Mallorca: an observational study
}

\author{
C. Ramis, R. Romero, and V. Homar \\ Group of Meteorology, Departament de Física, Universitat de les Illes Balears, 07122 Palma de Mallorca, Spain \\ Received: 16 February 2009 - Revised: 30 June 2009 - Accepted: 16 July 2009 - Published: 24 July 2009
}

\begin{abstract}
During the afternoon of 4 October 2007, a thunderstorm swept across the Island of Mallorca from southwest to northeast. Strong straight-line winds (up to $30 \mathrm{~m} / \mathrm{s}$ ) and heavy rain (rates up to $100 \mathrm{~mm} / \mathrm{h}$ ) were registered accompanying the storm. Tornadoes with an estimated intensity of F2-F3 developed nearby the city of Palma, severely affecting industrial installations. One person was killed by the impact of heavy debris while more than 10 million $€$ in damages were attributed to the event in the industrial area only. The observed evolution of temperature, humidity, wind and pressure, as well as the sequence of radar images, reveal that a squall line was initially organized over the sea and then moved north-eastwards at an estimated speed of around $80 \mathrm{~km} / \mathrm{h}$. This paper presents an analysis of the event from an observational point of view. The aim of the study is to contribute to the characterization of these rare events in the Western Mediterranean by analyzing the observational information available for this particular extreme event. The diagnosis is aimed at helping forecasters to identify this kind of organized deep convective events and being able to issue timely warnings. The synoptic scenario shows warm and moist advection at low levels over Balearics and an upperlevel trough over mainland Spain. This situation is known to be prone to deep convection in Mediterranean Spain in autumn. Radiosonde ascents from Murcia and Palma show convective instability at mid levels that can conduce to develop convection if appropriate ascents occur. A plausible lifting mechanism to trigger convection is attributed to large amplitude gravity waves, registered as short-period pressure oscillations by surface barographs.
\end{abstract}

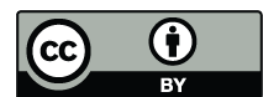

Correspondence to: C. Ramis (cramis@uib.es)

\section{Introduction}

The Balearic Islands, located at the centre of the western Mediterranean (Fig. 1), are known for their pleasant weather, especially during the warm period of the year. For this reason and for their holiday attractions, the Islands are among the best known touristic poles in Europe, with more than 10 million visitors per year. However, the Balearic Islands are affected, mainly during autumn, by hazardous weather events (Tudurí and Ramis, 1997). The period from September to November exhibits the annual maximum in thunderstorm occurrence (Gayá et al., 2001). Very occasionally these thunderstorms attain severe characteristics in the form of heavy rain, downbursts, hail and tornadoes. A recent heavy rain event occurred on 15-16 December 2008, when more than $250 \mathrm{~mm}$ in $24 \mathrm{~h}$ were collected in several sites in the mountainous area of Mallorca. In spite of its high potential impact, extreme phenomena associated with tornadoes have been, so far, either of weak magnitude, localized in space and time or have not affected densely populated areas. A statistical assessment of tornado reports for the 1989-1999 period shows, for instance, that only one out of the 27 events on record reached the F3 intensity in the Fujita scale (most lie in the F0-F1 category), while their paths rarely exceeded $8 \mathrm{~km}$ and none of them produced personal injuries or fatalities (Gayá et al., 2001).

A notable exception to these mild phenomena is the squall line that hit the island of Mallorca in the afternoon of 4 October 2007. In addition to the heavy rain and strong winds that affected extensive areas as the storm swept across the island, a post-storm damage survey indicated the impact of -at least- one tornado of F2-F3 intensity embedded within the parent system. Since the squall line crossed the city of Palma (450000 inhabitants) and industrial installations around town, the associated violent winds led to

Published by Copernicus Publications on behalf of the European Geosciences Union. 


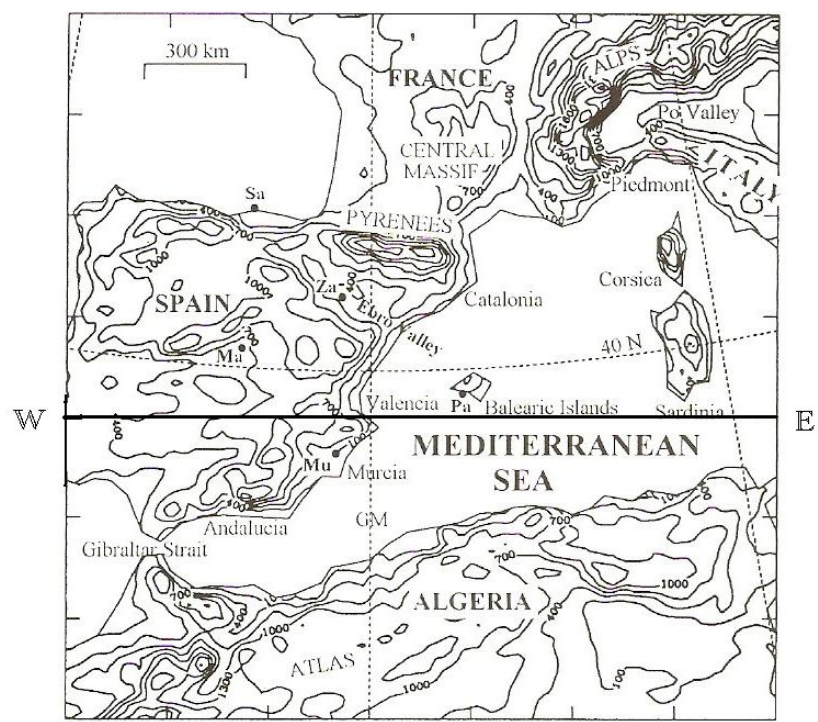

Fig. 1. The western Mediterranean region. Radiosonde stations used in the study are $\mathrm{Mu}=$ Murcia (08430) and $\mathrm{Pa}=\mathrm{Palma}$ (08302). The W-E line indicates the position of the cross-section presented in Fig. 8.

unprecedented traffic and social disruptions (Fig. 2), huge economical losses and even one fatality.

Quasi stationary organized convective systems with circular shape are not rare in the western Mediterranean area during the autumn and are frequently related to the heavy rain episodes that occur in that area (Riosalido, 1990). Convection organized in a linear form, such as a squall line, is not very common in south-western Europe and very few studies of this kind of damaging events exist. Ducrocq and Bougeault (1995) presented a numerical simulation of a squall line that crossed south-western France. Ramis et al. (1997, 1999) made an observational study of a squall line, with bow echo structure on the radar images, that moved from west to east over Catalonia (north-eastern Spain) and analyzed the meteorological context in which the severe linear convection developed. A notable aspect of the 4 October event is that the severe convection developed and evolved over the sea, whereas the previous cases reported occurred over land.

The aim of this paper is to gain insight on the mechanisms that triggered and sustained the organized convection on 4 October by using in-situ meteorological observations, satellite and radar imagery as well as lightning data. The study is aimed at improving the knowledge on the observational aspects of severe weather events in south-western Europe and particularly in the western Mediterranean. The examination of case studies, like the one presented in this paper, can help regional forecasters to identify severe weather events and issue timely warnings.

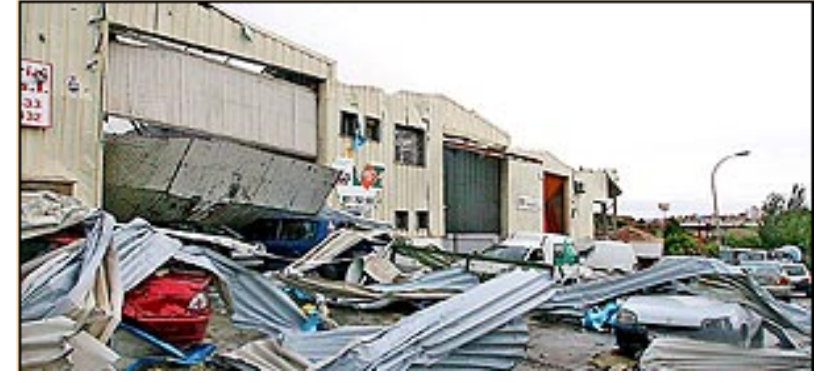

Fig. 2. Damage produced by the tornadoes in the industrial area close to Palma city.

The next section presents the event, Sect. 3 deals with the meteorological surface observations. In Sects. 4 and 5 we discuss and analyze the available satellite and radar imagery, as well as the synoptic situation and the vertical profiles, respectively. Finally, Sect. 6 presents the conclusions.

\section{The event}

On 4 October 2007 around 15:30 UTC, a thunderstorm coming from the south affected severely the island of Mallorca. The sky became spectacularly dark in a few minutes. In some parts of the cloud, a greenish tone was easily identifiable with naked eye (Fig. 3). The green thunderstorm was accompanied by strong and gusty winds from the south/south-west that affected the entire island. Previous observations of green coloured thunderstorms indicate that they are accompanied by severe weather (Gallagher et al., 1996; Wang, 2002). Greenness would be a consequence of reddened sunlight illuminating selective scatterers along the observer's line of sight or, alternatively, a consequence of the intrinsic blueness of clouds because of selective absorption by pure water, liquid or solid (Bohren and Fraser, 1993). Heavy rain also accompanied the passage of the 4 October thunderstorm. However, most of the damages were the consequence of strong gusty winds. A post-storm damage survey indicated the plausible scenario of one or more coexisting tornadoes of F2-F3 in tensity, which affected an industrial area located to the northwest of Palma. A man was killed due to heavy flying debris from a construction area blown by the strong winds. Damage in the industrial area was estimated at 10 million $€$ (from local press).

\section{Meteorological surface observations}

Several automatic weather stations registered the temporal variation of the meteorological variables at $10 \mathrm{~min}$ intervals (Fig. 4). Pressure records show patterns of special relevance. During the morning, pressure oscillations with changes up to $5 \mathrm{hPa}$ in one hour were registered, likely revealing the 


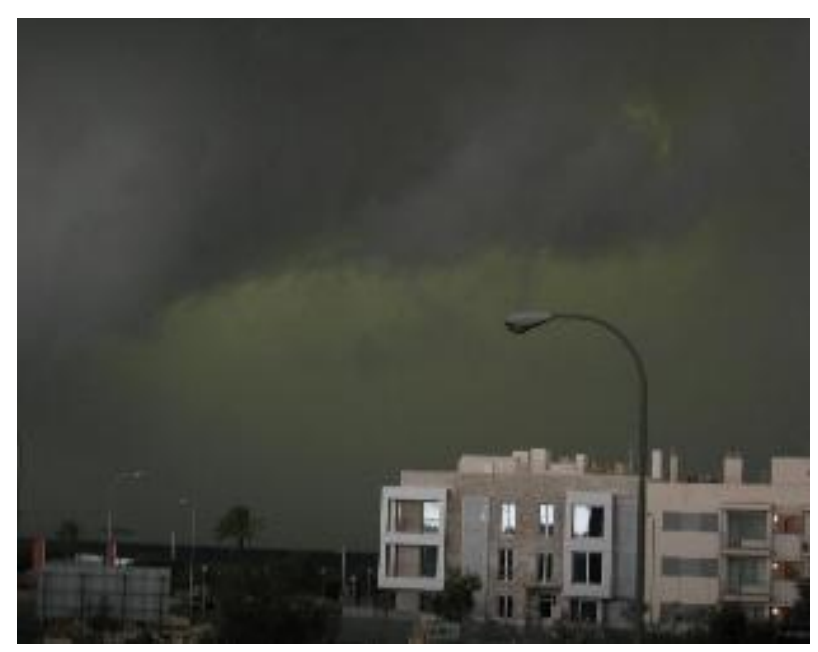

Fig. 3. Photograph of the thunderstorm from Palma city, looking towards the southwest. The greenish tones are evident.

presence of gravity waves ahead of the storm. Similar pressure oscillations were previously observed in the Balearic Islands (Monserrat et al., 1991) and associated with the onset of large amplitude forced seiches (known as rissagues in the Balearic Islands) in many ports and harbours of the archipelago (Ramis and Jansà, 1983). In fact, seiches of $1 \mathrm{~m}$ amplitude were observed in some ports of the Balearics during this episode.

Regarding the passage of the storm, a decrease of the pressure followed by a quick increase and posterior decrease were observed. Such characteristic signature matches the scheme of a pre-squall mesolow, shortly preceding the onset of heavy rain and strong winds, followed by a post-squall mesohigh (Johnson and Hamilton, 1988). Such pressure distribution was also observed in the squall line that crossed north-eastern Spain in 1993 (Ramis et al., 1999).

Temperature and relative humidity show cold air behind the storm as well as dry air accompanying the descending motions of the squall. These characteristic features can also be identified in other automatic weather stations of the archipelago. This allowed estimating an average speed for the storm of nearly $80 \mathrm{~km} / \mathrm{h}$ towards the north-east. Such speed appears to be in the upper range of the typical speeds observed for squall lines with bow echo structure (greater than $65 \mathrm{~km} / \mathrm{h}$ ).

\section{Remote sensing observations}

\subsection{Satellite imagery}

The Meteosat IR images for the morning of 4 October show convective activity about $200-300 \mathrm{~km}$ southwest of the Balearic Islands moving to the northeast. It appears to be a connection between the train of thunderstorms and the occur-
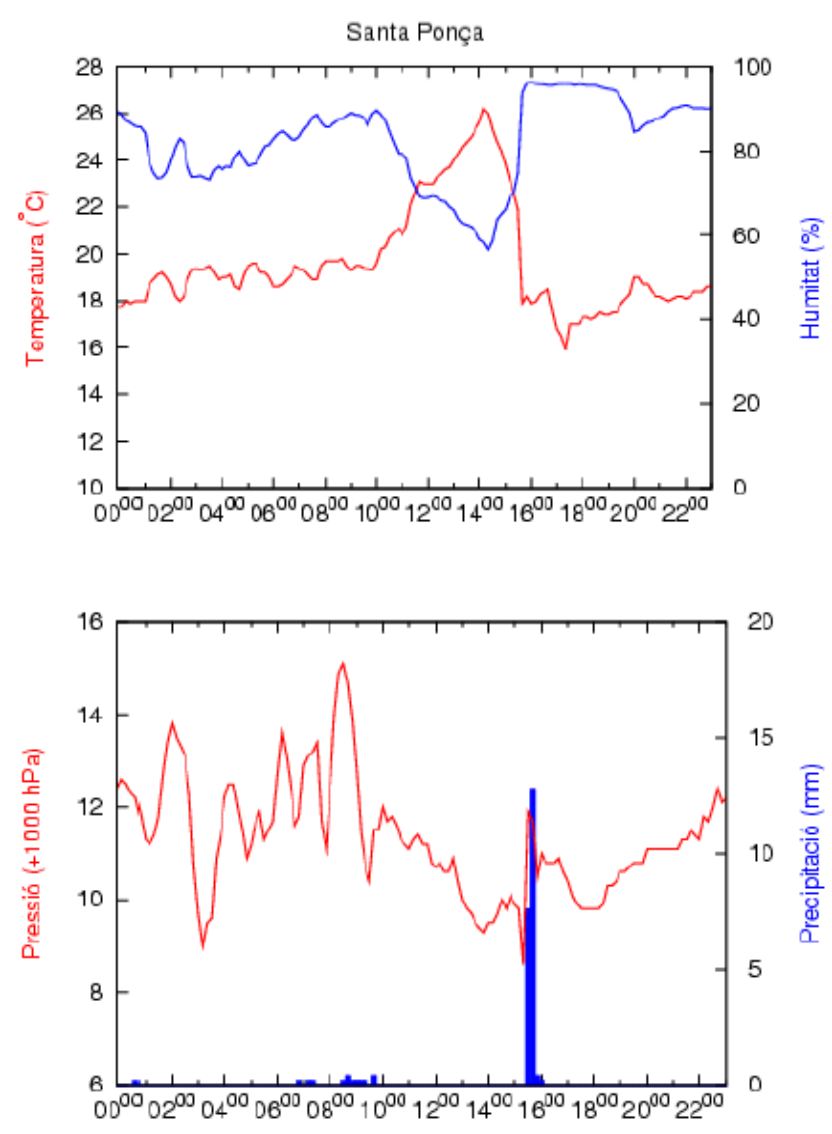

Fig. 4. Meteograms of temperature and relative humidity (upper panel) and pressure and precipitation (lower panel) during 4 October 2007 at an automatic weather station located in the west of Mallorca. One register every $10 \mathrm{~min}$ is available.

rence of gravity waves that would have been responsible for the pressure oscillations indicated before (Fig. 5). Around 10:00 UTC a new thunderstorm initiated offshore Murcia (mainland Spain, see Fig. 1), about $300 \mathrm{~km}$ away from Mallorca. This thunderstorm progressively became highly organized and $5 \mathrm{~h}$ later arrived to Mallorca from the south, exhibiting very cold cloud tops and impressive overshooting (Fig. 5).

\subsection{Radar imagery}

Unfortunately, the radar currently operational in Mallorca was not functional during those days. The only information available comes from the radars located in Valencia and Catalonia, in mainland Spain, around $200 \mathrm{~km}$ to the west and northwest of Balearics, respectively. The beam height at those ranges is approximately $2 \mathrm{~km}$, and therefore the reflectivity information available is only partial for this storm. Nonetheless, a clearly defined linear structure of the system, of about $50-60 \mathrm{~km}$, is still detected (Fig. 6) with the strongest echoes in its central part. In addition, a certain bow echo 

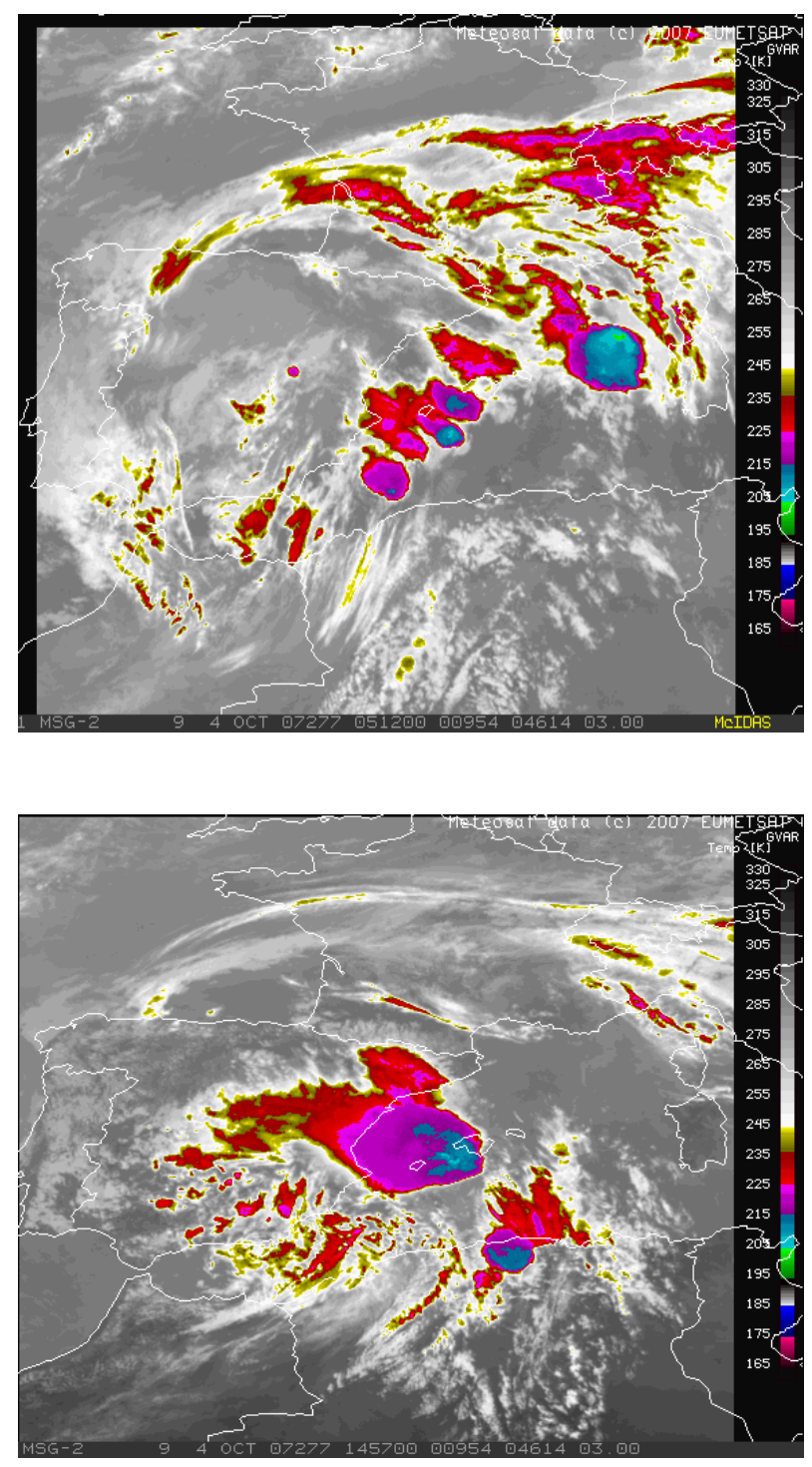

Fig. 5. IR MSG images on 4 October 2007 at 05:12 UTC (left) and 14:12 UTC (right). Colours indicate temperatures.

structure is observed in the radar image although no rear inflow notches can be clearly identified at those levels. At such long ranges, the Doppler signal is heavily aliased and no estimate of the radial wind field associated with the thunderstorm is available. Information from the LINET lightning detection network also shows a linear structure of the lightning strokes when the disturbance arrived in Mallorca (Fig. 6). Therefore information from both radar and LINET networks adds upon the evidences that the convection of 4 October was organized as a squall line.
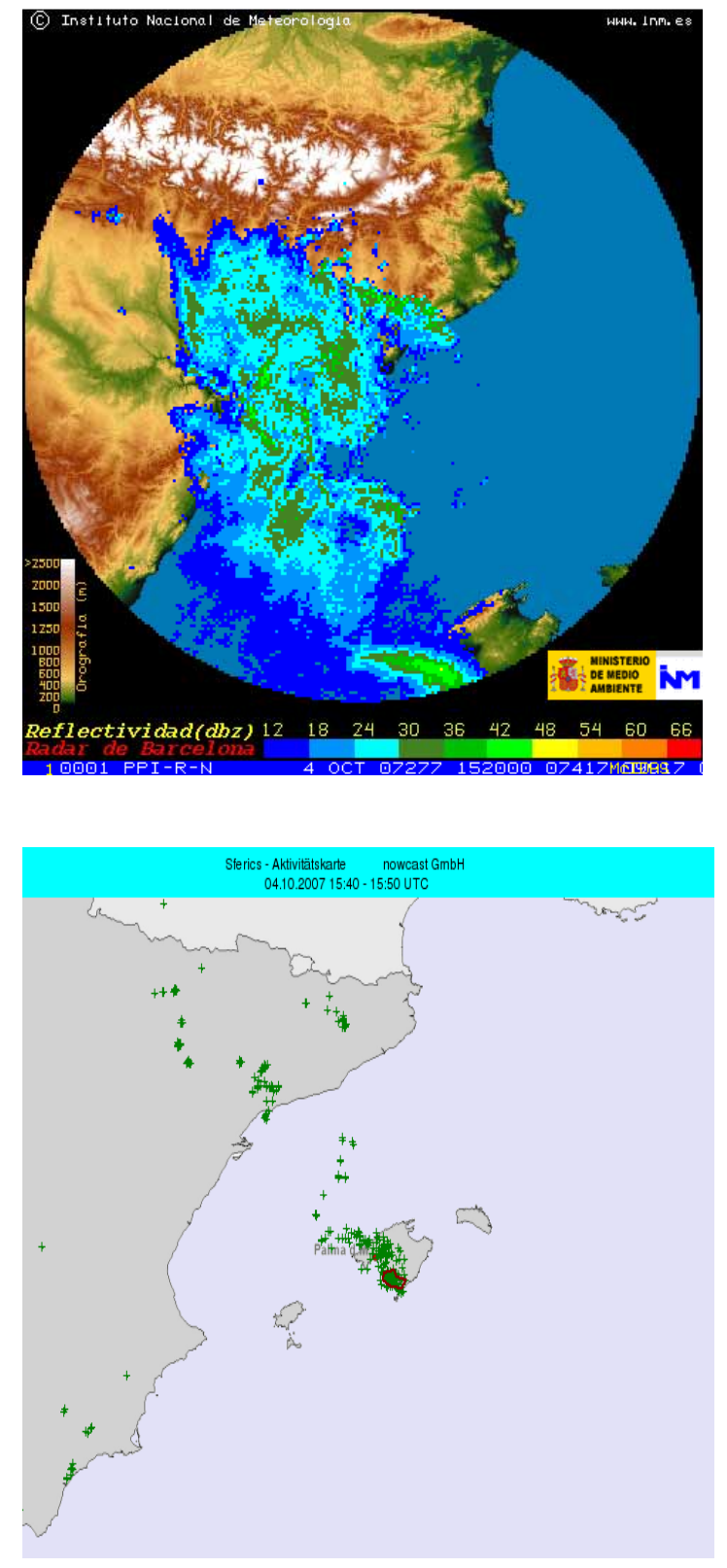

Fig. 6. Radar image from Barcelona on 4 October 2007 at 15:20 UTC (top) and sferic information of lightning strokes between 15:40 and 15:50 UTC (bottom).

\section{Meteorological situation overview}

\subsection{Synoptic overview}

The severe weather event occurred under a synoptic scenario dominated by a cold upper-level low over mainland Spain and a negatively tilted ridge over Corsica and Sardinia. Both systems produce a southerly to south-westerly jet over the western Mediterranean (Fig. 7). At low levels a weak low pressure area located to the south of the Balearics, 

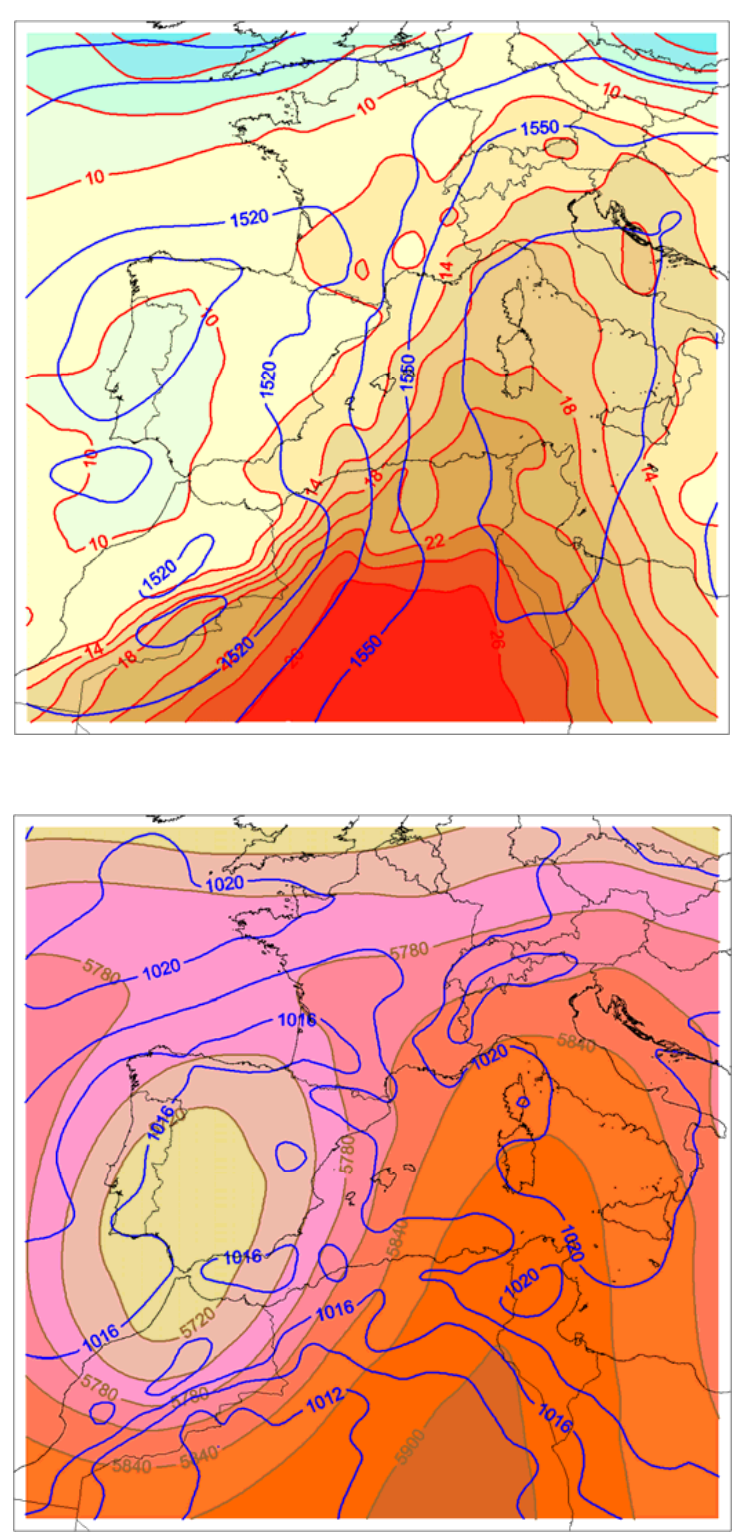

Fig. 7. Meteorological situation from ECMWF on 4 October 2007 at 00:00 UTC. $850 \mathrm{hPa}$ geodynamic height (blue contours) and temperature (colour filled contours) (top), $500 \mathrm{hPa}$ geodynamic height (colour filled contours) and sea level pressure (blue contours) (bottom).

combined with an anticylone over Italy, brings warm and moist air towards the islands and the eastern coast of mainland Spain (Fig. 7). The baroclinicity in the area between the Balearics and mainland Spain is quite evident. A warm front with a westward displacement is depicted in the temperature field over the Balearics while a cold front is located over the Alboran Sea and northern Africa. Reanalyses of plotted charts (provided by Agencia Estatal de Meteorología of Spain; AEMET) demonstrate the presence of a weak but well defined low at $850 \mathrm{hPa}$ over the Alboran Sea that moved

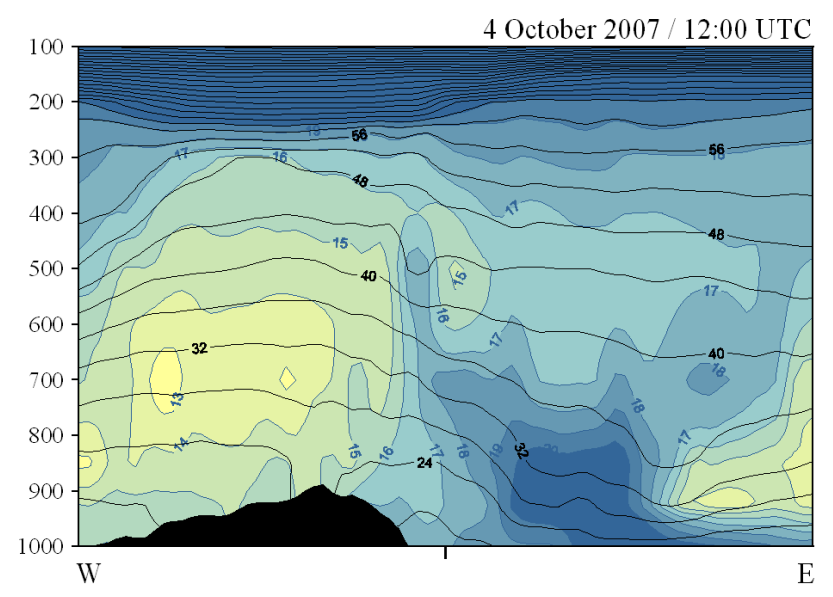

Fig. 8. Cross-section along the W-E line indicated in Fig. 1. Black lines: potential temperature. Blue lines and shaded: wet-bulb potential temperature.

towards the north, favouring the warm advection over the area between Balearics and the Iberian peninsula. The jet at upper levels is also very well defined. This jet backed from the south to the south-east over the Balearics during the morning of 4 October. This synoptic scenario is known to be conductive to deep convection, heavy rain and sometimes flash-floods in Mediterranean Spain, especially in early autumn when sea surface temperature is very high and favours evaporation. Interaction between the easterly humid flow and the coastal topography often determines where and when intense precipitation occurs (Romero et al., 2000; Homar et al., 2002; Ramis et al., 1998; Jansà et al., 2001).

The simultaneous presence of a south/south-westerly upper level jet and African air surge at low levels over the western Mediterranean Sea has been identified as the scenario favourable for the genesis of gravity waves that produce high frequency pressure oscillations (Ramis and Jansà, 1983; Monserrat et al., 1991). Large amplitude gravity waves have been pointed out as a lifting mechanism strong enough to trigger convection in the western Mediterranean in rissagues scenarios (Ramis and Jansà, 1990) as well as in other parts of the world. For example Uccellini (1975) documents a case of triggering of severe convection over the Central United States caused by pre-existing gravity waves. The high frequency and large amplitude pressure oscillations registered in the island's automatic weather stations (Fig. 4) confirms the presence of largely amplified gravity waves travelling across the region from the previous day.

Analyzing together the synoptic charts and the Meteosat images, it seems clear that thunderstorms developed in the warm sector of the aforementioned frontal system, over or just to the east of the strongest baroclinic area. Squall lines usually develop in the warm sector, some $100-200 \mathrm{~km}$ ahead of the cold front. The convective organization is favoured 

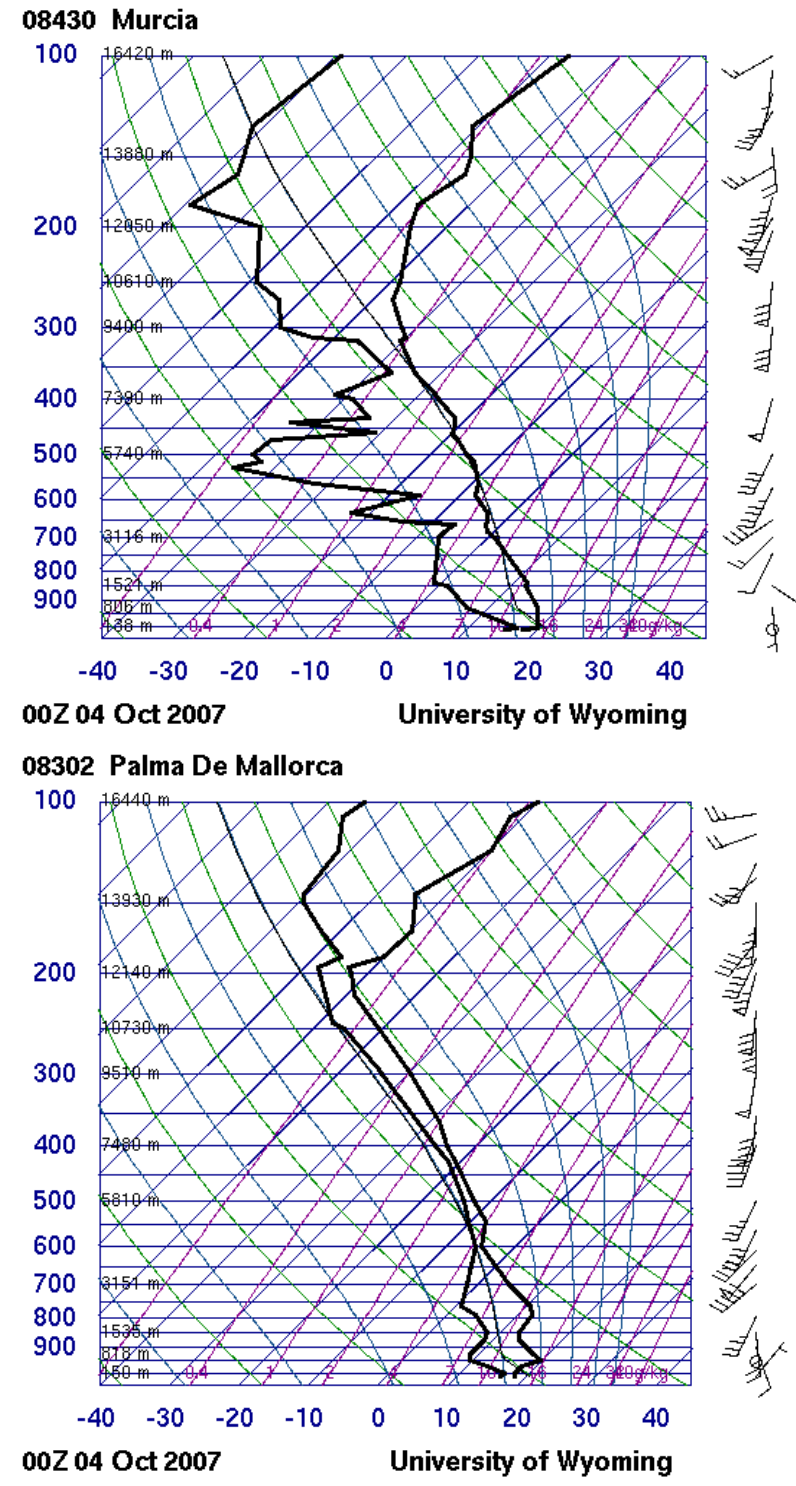

Fig. 9. Upper air observation on 4 October 2007 at 00:00 UTC. Murcia (top) and Palma (bottom).

if the cold front is a kata-front (Browning, 1986) since the descending motion ahead of the front can produce a dry layer that promotes severe convection. The character of the front has been studied by means of cross sections of potential and wet-bulb potential temperatures using data from the ECMWF analysis (Fig. 8). The analysis of the cross sections shows the presence of the warm air over the Mediterranean and cold air over the Iberian peninsula. Over the Mediterranean sea the potential temperature profile shows a transition from higher static stability at low levels to weaker stability at upper levels. Wet-bulb potential temperature distribution reveals the different character, in terms of humidity, of the Iberian and Mediterranean air masses. Some indica-

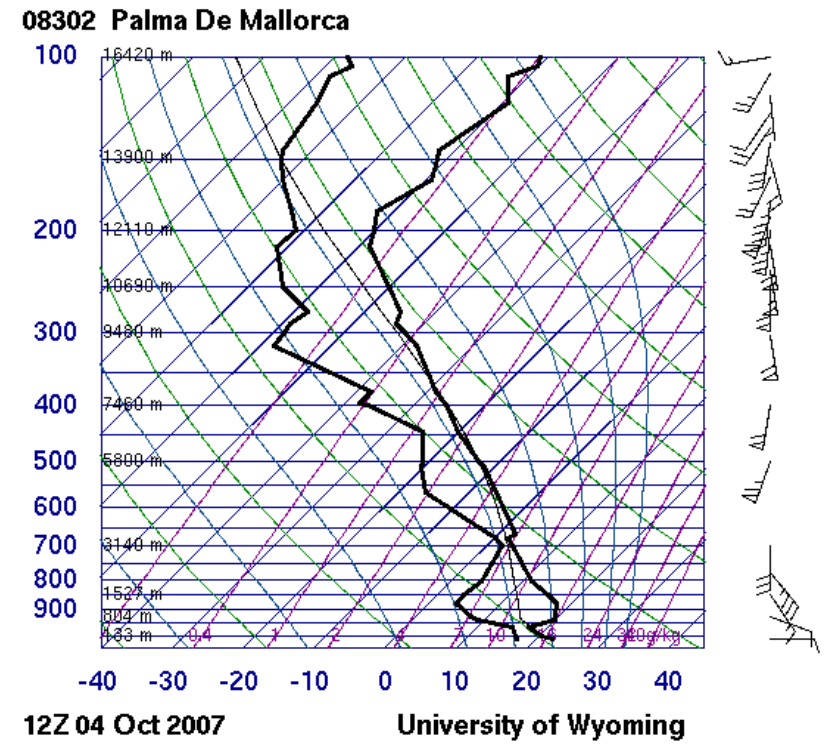

Fig. 10. Upper air observation on 4 October 2007 at 12:00 UTC in Palma.

tion of the kata structure of the front can be inferred since a tongue of dry air overlies the surface front and sits over convectively unstable air. However, the effective resolution of the analyses does not provide enough mesoscale details.

\subsection{Vertical structure of the atmosphere}

Radiosonde data in the area of interest are available from Murcia (in mainland Spain, nearby the genesis location of the storm, Mu in Fig. 1) and from Palma (where the thunderstorm became severe, Pa in Fig. 1).

The sounding from Murcia on 4 October 2007 at 00:00 UTC (Fig. 9) shows a temperature profile quite stable for the surface or near surface parcels $(\mathrm{CIN}=153 \mathrm{~J} / \mathrm{kg}$, CAPE is $62 \mathrm{~J} / \mathrm{kg}$, total's total index ${ }^{1} 43$ ). Moisture content in the troposphere is not particularly high (precipitable water is $22 \mathrm{~mm}$ ). The layer between 450 and $320 \mathrm{hPa}$ possesses very weak vertical stability (see Fig. 11) and strong wind shear (a transition from 50 to $70 \mathrm{kn}$ in wind speed is observed between these levels). The Richardson number ( $\mathrm{Ri}$ ) in the mid-upper troposphere over the south-western Mediterranean could well be below 0.25 - a critical value for gravity wave growth from linear theory (Hooke, 1986) - since calculated Ri values from the raw sounding data achieve 0.28 at $430 \mathrm{hPa}$. Additionally, a dry layer can be identified around $500 \mathrm{hPa}$, suggesting also the kata character of the cold front underneath.

\footnotetext{
${ }^{1}$ The total total's index (Miller, 1972) is defined as $T T=T_{850}+T d_{850}-2 T_{500}$ where $T_{850}$ and $T_{500}$ are the temperatures $\left({ }^{\circ} \mathrm{C}\right)$ at 850 and $500 \mathrm{hPa}$, respectively, and $T d_{850}$ is the dew point temperature $\left({ }^{\circ} \mathrm{C}\right)$ at $850 \mathrm{hPa}$, When $T T>49$ thunderstorms are likely.
} 

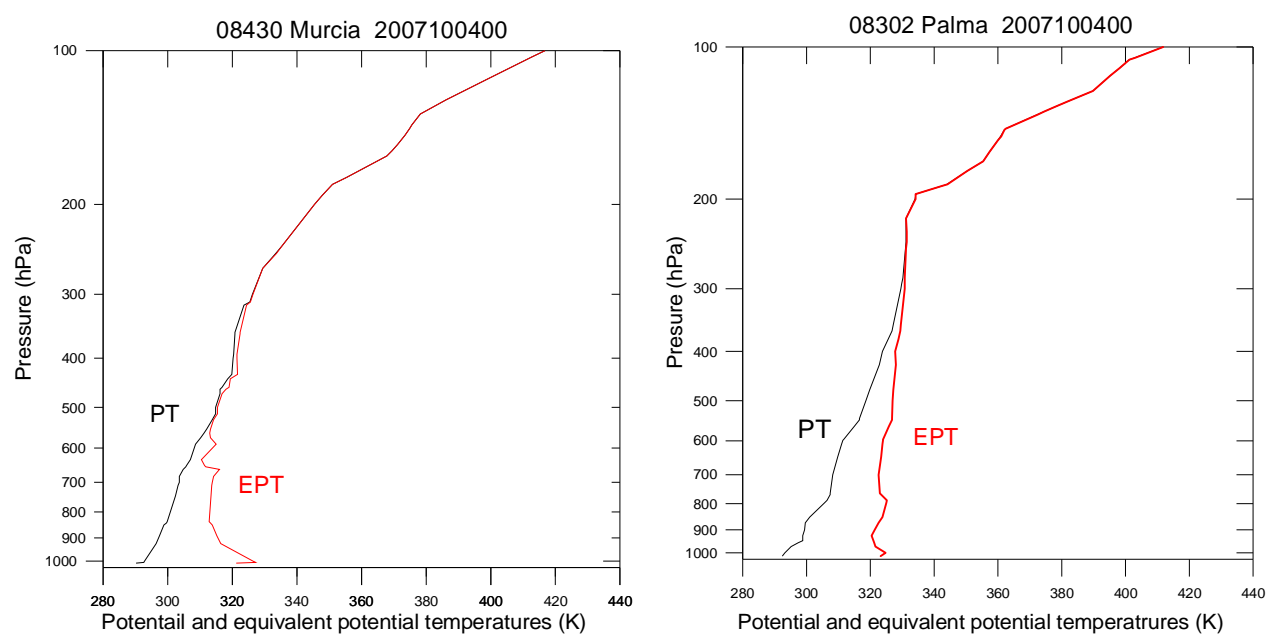

Fig. 11. Vertical profile of potential temperature (black) and equivalent potential temperature (red) on 4 October 2007 at 00:00 UTC over Murcia (left panel) and Palma (right panel).

The sounding from Palma on 4 October at 00:00 UTC (Fig. 9), representative of the warm air mass, depicts a very stable profile for surface or near surface parcels (CAPE is $0 \mathrm{~J} / \mathrm{kg}$, total's total index 46). Humidity is very high throughout the troposphere (precipitable water is $35 \mathrm{~mm}$ ) since Palma is located far enough from the cold front. Vertical stability is weak at the top of the troposphere, between 300 and $200 \mathrm{hPa}$ (see Fig. 11). This layer also shows strong vertical wind shear (wind changes from from 50 to $70 \mathrm{kn}$ ). Upper level weak vertical static stability and strong wind shear both help to define favourable conditions for gravity waves sustainment.

Twelve hours later $(3.5 \mathrm{~h}$ before the thunderstorm arrived in Mallorca), the sounding from Palma (Fig. 10) shows notable differences. Stability for surface or near surface parcels remains, as a consequence of the strong inversion close to the ground (CIN is $355 \mathrm{~J} / \mathrm{kg}$, CAPE is $38 \mathrm{~J} / \mathrm{kg}$, total's total index 45). Precipitable water is still high $(32 \mathrm{~mm})$. A LID (inversion capped by a layer with reduced stability; Farrel and Carlson, 1989) can be identified that favours the development of severe convection if the inversion can be overturned by vertical motions. Humidity has decreased at middle levels. The layer between 740 and $580 \mathrm{hPa}$ presents strong convective instability (Fig. 11), such that an ascent of the column of $150 \mathrm{hPa}$ would imply destabilization and convection could develop. Convective initiation of a two-dimensional squall line at mid levels that further covers the troposphere was analyzed by Buzzi et al. (1991) using a sounding from Palma that exhibits a vertical profile very similar to the present sounding. Vertical shear is also strong close to the base of the layer with convective instability. If gravity waves develop at midtropospheric levels ( $\mathrm{Ri}$ at $500 \mathrm{hPa}$ lies around 0.05 ), the inversion close to the ground acts as a resonance box amplifying the pressure oscillations (Gedzelman and Rilling, 1978;
Monserrat and Ramis, 1990). This mechanism might explain the highly amplified pressure fluctuations detected at the automatic weather stations (Fig. 4).

\section{Conclusions}

An analysis of the meteorological conditions under which an event of severe weather developed over the western Mediterranean on 4 October 2007 is presented. The island of Mallorca was affected by strong winds and heavy rain. One or two tornadoes, with F2-F3 intensity, affected an industrial area close to the city of Palma, killing one person and producing high social and economic impact.

Surface observations from automatic weather stations of pressure, temperature, humidity, rain and wind during the thunderstorm are in a good agreement with the model of a squall line. Radar and sferic information demonstrate the linear organization of the convective system. Ahead of the main line, pressure records in Mallorca show large amplitude oscillations with short period that are attributed to tropospheric gravity waves. Meteosat images show that convective clouds are compatible with the hypothesis of gravity waves.

The synoptic setting for this event is defined, at low levels, by the presence of warm air over the Balearics and a cold front over the Alboran Sea and southeast Spain. At upper tropospheric levels a jet from the south-southwest is identified. Such situation matches with previously identified cases of gravity wave occurrences in the western Mediterranean, often accompanied by severe convection. That scenario includes a layer of warm African air at relatively low levels that overruns the colder and humid Mediterranean air just above the surface. This signature is reflected in the Palma sounding as a strong inversion at low levels. Low vertical stability and 
strong vertical shear, both at mid-upper tropospheric levels, support the hypothesis of gravity wave formation.

The Murcia sounding at 00:00 UTC, very close to the location where the thunderstorm developed $10 \mathrm{~h}$ later, shows a dry layer at medium levels that suggests the kata character of the front. Indeed, the cross-sections from ECMWF analyses also support partially the kata type of the front. Therefore, once the thunderstorm developed in the warm sector, 100 $200 \mathrm{~km}$ ahead of the cold front, it may have found favourable conditions to attain a squall line structure. Strong wind shear aloft results in low Richardson numbers that characterize environments that support the generation of gravity waves.

Although no unequivocal evidences exist, most observations suggest the presence of highly amplified gravity waves that could have initiated convection. The amplitude of the gravity waves may have produced enough ascent for convectively unstable layers to release convection.

Both radar and satellite images reveal that the westernmost border of the linear structure interacted with the mountainous range of Mallorca. Could the orography, by increasing the low-levels drag, have influenced the development of locally intense helicity nuclei near the ground and so contributed to the formation of the tornadoes recorded in the city of Palma?

Further research using high resolution mesoscale nonhydrostatic models will be conducted in order to gain insight and better confidence on some of the hypotheses made throughout this observational study, possibly including the nature and origin of the gravity waves apparently associated with the triggering of the convection.

Acknowledgements. This research has been sponsored by MEC of Spain under grants CGL2005-03918/CLI (PRECIOSO) and CGL2005-05681/CLI (ENSEMBLE). Satellite pictures have been provided by EUMETSAT. Radar information has been provided by the AEMET of Spain. Hans D. Betz from University of Munich is acknowledged for giving access to the LINET Lightning Detection Network. Soundings were retrieved from the University of Wyoming.

Edited by: S. Michaelides, K. Savvidou, and F. Tymvios

Reviewed by: two anonymous referees

\section{References}

Bohren, C. F. and Fraser, A. B.: Green thunderstorms, B. Am. Meteorol. Soc., 74, 2185-2193, 1993.

Browning, K. A.: Conceptual models of precipitation systems, Weather Forecast., 1, 23-41, 1986.

Buzzi, A., Fantini, M., and Lippolis, G.: Quasi-stationary organized convection in the presenceof an inversion near the surface: experiments with a 2-D numerical model, Meteorol. Atmos. Phys., 45, 75-86, 1991.

Ducrocq, V. and Bougeault, P.: Simulation of an observed squall line with a meso-beta hydrostatic model. Weather Forecast., 10, 380-399, 1995.
Farrell, R. J. and Carlson, T. N.: Evidence for the role of the lid and underunning in an outbreak of tornadic thunderstorms, Mon. Weather Rev., 117, 857-871, 1989.

Gallagher III, F. W., Beasley, W. H., and Bohren, C. F.: Green thunderstorms observed. B. Am. Meteorol. Soc., 77, 2889-2897, 1996.

Gayá, M., Homar, V., Romero, R., and Ramis, C.: Tornadoes and waterspouts in the Balearic Islands: phenomena and environment characterization, Atmos. Res., 56, 253-267, 2001.

Gedzelman, S. D. and Rilling, R. A.: Short period atmospheric gravity waves: a study of their dynamic and synoptic features, Mon. Weather Rev., 106, 196-210, 1978.

Homar, V., Romero, R., Ramis, C., and Alonso, S.: Numerical study of the October 2000 torrential precipitation event over eastern Spain: analysis of the synoptic-scale stationarity, Ann. Geophys., 20, 2047-2066, 2002,

http://www.ann-geophys.net/20/2047/2002/.

Hooke, W. H.: Gravity waves, in: Mesoscale Meteorology and Forecasting, edited by: Ray, P. S., Amer. Meteorol. Soc., 272288, 1986.

Jansà, A., Genovés, A., Picornell, M. A., Campins, J., Riosalido, R., and Carretero, O.: Western Mediterranean cyclones and heavy rain. Part 2: Statistical approach, Meteorol. Appl., 8, 43-56, 2001.

Johnson, R. H. and Hamilton, P. H.: The relationship of surface pressure features tomthenprecipitation and air flow structure of an intense midlatitude squall line, Mon. Weather Rev., 116, 1444-1472, 1988.

Miller, R. C.: Notes on analysis and severe storm forecasting procedures of the Air Force Global Weather Control, AFGWC Tech. Rep. 200, Air Weather Service, US Air Force, 102 pp, 1972.

Montserrat, S. and Ramis, C.: Dynamic stability of a three layer model with discontinuous profiles of wind and temperature, J. Atmos. Sci., 47, 2108-2114, 1990.

Montserrat, S., Ramis, C., and Thorpe, A.: Large-amplitude pressure oscillations in the western Mediterranean, Geophys. Res. Lett., 18, 183-186, 1991.

Ramis, C. and Jansa, A.: Condiciones meteorológicas simultáneas a la aparición de oscilaciones del nivel del mar de amplitud extraordinaria en el Mediterráneo occidental, Rev. Geofísica, 39, 35-42, 1983.

Ramis, C. and Jansa, A.: Situación meteorológica a escala sinóptica y a mesoescala simultanea a ala aparición de las 'rissagues', IME, 27-38, 1990.

Ramis, C., Arús, J., López, J. M., and Mestres, A. M.: Two cases of severe weather in Catalonia (Spain). An observational study, Meteorol. Appl., 4, 207-217, 1997.

Ramis, C., Romero, R., Homar, V., Alonso, S., and Alarcón, M.: Diagnosis and numerical simulation of a torrential events in Catalonia (Spain), Meteorol. Atmos. Phys., 69, 1-21, 1998.

Ramis, C., López, J. M., and Arús, J.: Two cases of severe weather in Catalonia (Spain). A diagnostic study, Meteorol. Appl., 6, 1127, 1999.

Riosalido, R.: Satellite characteristics of mesoscale convective systems over Spain, Proceedings of the Eighth Meteosat Scientific Users Meeting, EUMETSAT EUMPO8, 127-130, 1990.

Romero, R., Doswell III, C. A., and Ramis, C.: Mesoscale numerical study of two cases of long-lived quasi-stationary convective systems over Eastern Spain, Mon. Weather Rev., 128, 
3731-3751, 2000.

Tudurí, E. and Ramis, C.: The environments of significant convective events in the western Mediterranean, Weather Forecast., 12, 294-306, 1997.
Uccellini, L. W.: A case of apparent gravity waves initiation of severe convection storms, Mon. Weather Rev., 103, 497-513, 1975.

Wang, P. K.: The Kansas green thunderstorm of 4 October 1998, B. Am. Meteorol. Soc., 83, 355-357, 2002. 